\title{
Challenge and its opportunity to deliver education through cloud computing environment in Ethiopia
}

\author{
Asebe Teka Nega \\ Wolkite university, collage of informatics and computing, wolkite, Ethiopia
}

\begin{abstract}
These days technology plays enormous roles in making day to day human activities easier. Previously established institutions need to reconstruct their data centers to run their business in an easy and comfortable manner. information and communication technologies (ICT) used for progressive improvement in the quality of education. in most developing country education disseminate rate is low with different factors poor of infrastructure, well engaged and capable teachers, geographical locations, different education tools, laboratories and also budgeting issues are the main challenges, as government higher education can invest more budget and they can deploy different clouds for a society at least one public university in one state have responded to deploy a cloud. they can distribute centrally different educational information's, books, and so on, again not expected that all schools are developing their own datacenter and full fill different computing infrastructure's which cost more instead with this scenario all schools including primary, secondary and university's mostly fourth-generation universities since they may take a lot of time to deploy their infrastructures until they can use another's universities cloud minimizing costs and manpower.
\end{abstract}

\section{Key word: - Cloud computing, ETHERNET}

\section{Introduction}

These days technology plays enormous roles in making day to day human activities easier. Previously established institutions need to reconstruct their data centers to run their business in an easy and comfortable manner. This would be a journey from more costly and time taking process to cheap, time saving and effective process. More importantly, cloud computing provides computing service to the user through the internet. Cloud computing is a computing system where a large resource pool of different computing systems is connected via a network to provide different service from inside or outside that domain [1][2]. With technology, the university can serve different materials for a society like the city municipal, state, zone, educational sectors, health center, an agricultural center, which must be supported by different universities .different studies stated the opportunities and the potential benefits of information and communication technologies (ICT) for improving the quality of education. information communications use a "major tool for creating respected societies" [3]. This could provide a way to show up the way for educational sectors to quality education for all. The main target establishment of higher education is to serve the community with different technology since they have more budget than other service sectors. In Ethiopian most higher educations have not such role to help the service sector with information communication technology, but they have to on the front to give different technology to the society. There are three cloud delivery models [4], Software-as-a-Service, Platform-as-a-Service and Infrastructure-as-aService And also, we have four deployment models, Public, Private, Community and Hybrid clouds [5].

\section{Statement of problem}

Governmental organizations found around Higher Institutions they haven't data center and research 
centers but they need to have and also this higher education is more related to service-based between Higher Educational Institutions, governmental organizations, new universities, and small Enterprises are low and separated. But they have less power to Launch and implementing data center and IT infrastructure in all individual government organizations are and it economically not feasible.to do this Higher Institutions have their own data center, research center, and IT Infrastructure that still they can't use this pore of infrastructures to solve society's problems

\section{Overview of Cloud computing}

Cloud computing is a computing system where large resource pool of different computing systems are connected via network to provide different service from inside or outside that domain. These pools of resources are requested depend on service demand, the user may ask for provider scalable variable or fixed infrastructure for dump on or use from the application, different data and file storage for execution of what individual or organization. With the advent of this technology, all services are given to the user based on SLA - the document that contains each and every detail that the cloud provider and the user are agree on. There are different cloud providers, Today, cloud computing paradigm has become one of the most interesting technologies with virtualization concept. This is a technique to create abstract layer of system resource and hides the difficulty of hardware and software working environment. Typically, as virtual machines with processing unit networking connectivity, storage, and bandwidth. Simply it is computer within a computer, implemented in software Virtualization commonly implemented with hypervisor technology. The cloud determines how those virtualized resources are delivered, allocated, and presented. In cloud, different applications and information is dump. It has many benefits over traditional data center. As cloud defined in [5] attributes for delivering computing services are:

* It uses Internet to offer elastic services which is dynamically get resource on different workload;
It provides a massive infrastructure to support elastic services;

The resources used for in the service have charged accordingly;

The security and maintenance service are offered by cloud providers;

It is cost-effective due to resource multiplexing.

There are three cloud delivery models:

Software-as-a-Service

Platform-as-a-Service and

Infrastructure-as-a- Service

And also, we have four deployment models:

Public

Private

Community

Hybrid clouds.

\section{Advantage of cloud computing}

Cloud computing technology is a modern technology which is used by a different governmental and private company with having the different advantage that comes through get business profit for the company

Very fair price for hardware: you may not be expected to purchase full computer which is very expensive instead you can rent only the computing resource through internet based on the service level agreement

You can get high performance computing: when you get rent that is based on your plan that how many you can afford .no programs or files are dumped on your personal computer; any user save time on switching on and switching off his/her computing device

Fewer maintenance costs: since your software and hardware is under a cloud you may not worry about maintaining cost since based on SLA provider is responsible to create a conducive computing environment

Very fair price for software: in cloud, there is SAS that anyone can have requested software he /she needs to be installed in the system, this software are you may not request the full price that is a full package since they deliver for users there is no need to purchase software packages for each computer in the organization. 
* Increased computing power: When using cloud computing, you can use cloud computing power since you are no longer limited to what a single desktop computer can do.

* Your data is more of secured: -: since your data is stored in the cloud you may not wary where is the place, every time your data is more secure

* Your data is near to you: in the cloud, you may not wary about storage or any hardware whenever you go to your destination your data is near to you

\section{Education sector in Ethiopia}

Education is mainly for human being to develop their brain and make and create a civilized society that's more effect on country's social and economic settlement [9]. In Ethiopia we try to pass different level of education cycle to achieve one's human being interest or demand that are inserted in the economy. In Ethiopia education system are limited and inequitable access, lack of quality and relevance, and continuous decline in quality and standard. Since most of the schools are located in the cities rather than countryside. but most of population in Ethiopia are live and found in rural area which have very poor infrastructures as well as poor almost null of technologies usage and most of the people live in this area are low educational opportunity having visible gaps between regions, urban and rural sectors. In general, there are different problem I try to list below that delivering education in Ethiopia.

* Limited Access: Ethiopia is one of a developing country, mostly in Ethiopia education is deliver with face to face teaching-learning style without real lab installation and some education sector that found in the main city may have full of access for educators, as developing country almost $90 \%$ of residence gets in the country side having poor access of education

* Less equitable for different state: In Ethiopia, there is a limited expansion of the school. the actuality of education is also extremely inequitable; huge gaps existed between regions, genders, and above all between urban centers and rural areas. Because of the different states have a shortage of budgeting issues on allocating for different educational levels. There were hardly any schools in the countryside. As a result, the people of the countryside residence and the children had no educational opportunities.

Poor Efficiency: Most teacher need to create their residence in cities that are more off get full infrastructure for their future carrier and also because less salary most teacher needs to change their proficiency. having this different challenges in country side because of shortage of teachers, the government try to propose anew polices that from grade 1 to 4 are deliver education with only one teachers, thus are more of getting very poor efficient to deliver education in appropriate A high rate in the number of dropouts and repeaters indicates the inefficiency of the educational system itself. During the previous educational systems

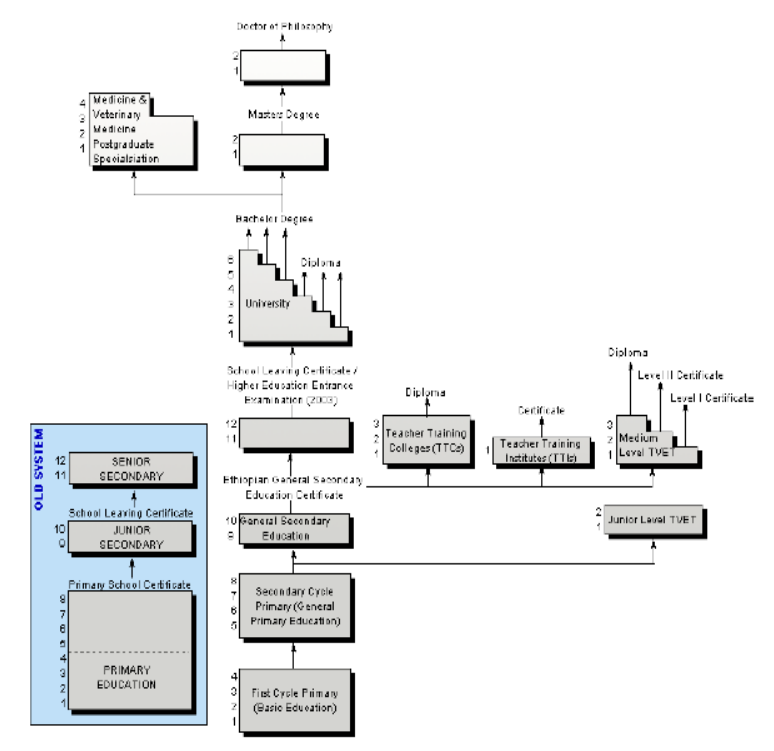

Fig: - [8] The Structure of Education in Ethiopia

\section{Cloud in Ethiopia}

Earlier Claude technology is less known by most of Ethiopian company but now different compony try to create their own cloud integrated with foreigners' company and local companies like Ethiopian telecommunications among them are websprix, codigital, symbol technologies. IE network solution, MKTY information technologies, Kenera international trading, UTC solution and so on. As a government they try to link different public university, currently, there are 45 public universities, ministry of education put a budget for facilitating internal work activities. HEIs are being built-in very 
high-speed cloud connectivity for sharing differen $\mathbb{V}$ resources to serve education more of in quality. Without delivering quality education, the country may not achieve the GTP goal. Education should deliver with updated technologies special with information communication technologies. to gev more quality education the Ethiopian government is investing in millions every year.in HEIS there is ar ICT class that they develop as a national wide the so $\sqrt{ }$ called ETHERNET which cost almost more than 2 billion birrs connected the first to third generation university 31 in number which has a plan to expand this project (creating a highbred cloud) with the fourth generation university 13 in number support education in higher education institutions with technology. Before these projects, the government tried to implement a school net to distribute education through plasma mainly advantage for countryside students. However, due to the small budget, it is not able to supply the full ICT infrastructure requirements of all universities. Requirements were a little bit solved using cloud computing this proposed system was e high bride which means a combination of private and public. The private cloud is for collaborating higher education institutions. any kind of information shared with one university any university that are members of this cloud can access the information. Any through this cloud they can share different softcopy books from different universities treated as a local network. to make more of a hybrid cloud they try to avoid the security issues even if most of the university is fear of that. since critical and sensitive data could be owned by university members and responsible bodies from the Ethiopian Ministry of Education.

\section{Methods of the study}

We try to follow different research Methodology of the Study to materialize the objectives my research,

* Research Study: The research purpose is going towards an experimental approach as insights are being searched within companies. Some of the principal ways are:

$\checkmark$ A search of the literature Interviewing experts in the subject the study is associated with a deductive approach, as existing theory is tested.
Unstructured questions were asked to the interviewees to get as much valid data as possible.

Development Environment and programing Tools. This study will be using the following hardware and software

Open stack cloud platform

Oracle Virtual box

XEN Hypervisor

Cloud simulator

Microsoft office 2019

Java Programing Language

Is cloud solve education challenge in Ethiopia?

Yes, it improve some challenges of educations hence to my view use, university's information technology capacity for the societies for the selected educational sectors and service sectors to minimize economically most of universities and education sector have small budget, which give for those universities infrastructure as a service like renting different resources (hard disk, RAM, processor ), platform as a service (like different operating system, development tools) and software as a service (different software's like student management, inventory management, and so on ) by establishing private cloud with different phase. Cloud scalability and elasticity and the IaaS and SaaS service models are a perfect fit for addressing the trends and challenges. Cloud services allow upgrade universities capacity by saving cost for deploying a huge investment to facilitate learning systems

\section{Opportunities to adaption cloud for Ethiopian educational sectors}

In Ethiopia cloud computing have many opportunities especially applying cloud in educational sectors, Ethiopian education are mainly collected in central city, but as I try to say in previous most Ethiopian population are gathered in urban side having less infrastructure of education and also lee educated teachers, with a cloud opportunity one of them are E-learning and e-education service: .since in Ethiopia, most of the place is geographical located far from the main city the government have a shortage of budgeting to create full privilege in educational sectors most of the countryside student is get poor of quality education and the teacher also have not to get update themselves with the current 
technologies. this cloud technology role is giving different service provisions for every day to day life activities. now the government is looking to distribute different digital services to enhance its citizen's lives style in a good manner, having this opportunity educational cloud computing answer best demand changes in their activities. one's good cloud provider whether a governmental or a privet provider deploy in educational sector they have the chance to collect or create different business opportunity and deliver good quality educations for Ethiopian citizens especially in movement schools that are found in countryside or abroad of the main city, there is no any laboratory or practical tools within this cloud technologies they can access or use SAS, PAS. IAS all of this service can access easily [8]. in Ethiopia, scalability acts as a very influential fact against IT demand changes. This requirement leads to improve IT service provision. Again, in this cloud technology when you create this opportunity, it means deploying a cloud for public or government customers will pay depending on their service usage. Another opportunity, in addition, to delivering quality education as an opportunity to deploy cloud, as a businessman there are different unexpected cost when you use physical computing power and also, they cost more but if we use this technology c service scalability, by, IT infrastructure needs to respond to unpredicted demand will be decreased. In addition to this will occur due to service transition to cloud computing. different computing costs such as upgrading, infrastructure, and different operational costs will be decreased by using cloud computing. Efficiency in the use of IT: and the last opportunity is availability issues that anywhere you go just you think that always your data is near to your tore

\section{Challenge Adaption of cloud for Ethiopian educational sector}

As opportunity, I try to state in the above that in Ethiopia there is as such good cloud provider, in case if more provider is getting through there may be a security vulnerability that no one can be preferred to put his or her data through the cloud The remote usage of Information Technology resources needs trust with customers to include the external cloud. It can be very hard to set up a security architecture that measures such a trust boundary without introducing vulnerabilities [6]. this thing also happened on the current governmental cloud Hybridge cloud ETHERNET most public university are pretended to put data on this cloud because of security issues, the other one is there are a high transitions of business data as it is their request you more storage size data it may have an opportunity for big data but a challenge for cloud. if a private cloud is put his hand to educational sectors it may also reduce operational governance control that is lower than that over onpremise Information Technology resources. This introduce you risks related with how the cloud provider manages its cloud, as well as the external connections that are required for communication between the cloud customer and the cloud [6]. Ethiopia there are a few cloud providers even if they have small infrastructure, if this opportunity getting for foreigners' compony internal company may be out of the market even the government may prefer to use international provider rather than a local one. in another scenario when applying cloud as the government there is a big challenge on budgeting and capable IT professionals to apply this technology.

\section{Summary of the study}

Education in Ethiopia is big tools to that extent the country plan to reach the goal which is stated in GTP , technology is the one that facilitates this GTP, in most developing country education disseminate rate is low with different factors poor of infrastructure, well engaged and capable teachers, geographical locations, different education tools, laboratories and also budgeting issues are the main challenges, as government if they deploy at least 11 different clouds for each of state at least one public university have responsible to deploy a cloud and with these different state they create a model to create a hybrid cloud that control as government, they can distribute centrally different educational information's, books, and so on, again not expected that all schools are developing their own datacenter and full fill different computing infrastructure's which cost more instead with this scenario all schools including primary, secondary and university's mostly ( fourthgeneration universities:_ since they may take a lot of time to deploy their infrastructures until they can use 
another universities cloud ) and private schools can rent this service. government higher education sector can afford to deploy this kind of data center even not only for the educational sector if one university deploy private or public cloud, they can give service for a different stated and municipal organization which is the other side of generating business for the university

\section{Reference}

[1] Nicolae Paladi, "Trusted Computing and Secure Virtualization in Cloud Computing", thesis in Swedish Institute of Computer Science, 2012

[2] J. Hurwitz, R. Bloor, M. Kaufman, and F. Halper, , "What Is Cloud Computing," 2015. [Online].

[3] UNESCO Communiqué of the ministerial roundtable on 'Towards Knowledge Societies' UNESCO Paris 2003

[4] D. C. Marinescu, Cloud Computing Theory and Practice Cloud Computing Theory and Practice, Nework: Elsevier In, 2013 , p. 132

[5] Md Rabbani, "Resource Management in Virtualized Data Center", Waterloo, Ontario, Canada, 2014

[6] Thomas Erl with Zaigham Mahmood and Ricardo Puttini, "Cloud Computing Concepts Technology\& Architecture - The Prentice Hall Service Technology Series”, pp. 45.

[7] The Educational System of Ethiopia (International Education Association of South Africa - IEASA 12th Annual Conference 27th - 30th August, 2008

[8] Cloud Computing: Barriers to Adoption",Available online: https://www.sei.cmu.edu/sos/research/cloudcomputi ng/cloudbarriers.

[9]. Education Sector Development Programmed V (ESDP V) 2008 - 2012 E.C. 2015/16 - 2019/20 G.C 